\title{
A Comparative Study of Sino-America Family Education From the Perspective of Culture
}

\author{
Lina Yuan and Yunling Sun*
}

\author{
College of Humanities and Sciences of Northeast Normal University \\ *Corresponding author. Email: 422820075@qq.com
}

\begin{abstract}
Aiming at exploring the similarities and differences in Sino-American family education, this paper tries to carry out a comparative study on Chinese and American family education in terms of notion, content and method from the perspective of culture. To absorb advanced American family education concepts and cultivate more talents for Chinese society, the author looks forward to the improvement and integration of two systems, and wishes the family education in our country more reasonable and perfect.
\end{abstract}

Keywords: Family education, Cultural difference, Comparison.

\section{INTRODUTION}

Chinese and American education can be regarded as two extreme of education, one is too much criticism, the other is praise too much, so the real fit is the combination of the two. China and the United States have great differences in terms of cultural traditions, thinking, lifestyle, and social customs, resulting in differences in educational methods, educational content, and educational purposes between China and the United States. Therefore, aiming at exploring the similarities and differences in Sino-American family education, this thesis tries to carry out a comparative study on Chinese and American family education in terms of family education notion, family education content and family education method from the perspective of culture. To absorb advanced American family education concepts and cultivate more talents for Chinese society, the author looks forward to the improvement and integration of two systems, and wishes the family education in our country more reasonable and perfect.

\section{PREVIOUS STUDIES ON FAMILY EDUCATION AT HOME AND ABROAD}

In modern China, the research on family education was more valued by people. The modern theoretical system of family education science has been established and a series of monographs on family education have emerged. The great pioneer of the proletarian culture, Mr. Lu Xun, is very concerned about and attaches importance to the theoretical study of family education. Mr. Lu Xun deeply and penetratingly discussed the theory of family education in many books. Some articles, such as "How do we be fathers now" and "How do we educate children?" may even be said to be monographs of home education. Of course, there are still some studies that criticize domestic family education. In monographs, such as the "China Critique of Parents" edited by Feng Lin, through interviews with experts, scholars, teachers, community members, and parents in education, the current status, concepts, thoughts, and methods of Chinese family education are discussed. In addition, there are "Chinese Children Missing What" by Yu Fan and Huang Xu's "Current State Education Report", which all reflect the problems in our country's family education.

The ideas of family education abroad also have a long history. Starting from the period of rising capitalism, the establishment of a modern pedagogy and psychology system has effectively promoted the study of family education theories in countries around the world. The famous British philosopher Locke published the book Homeschool (also translated as Educational Talk) at the end of the 17th century. In his book, Locke expounded his views on education from the aspects of virtue, wisdom, physical and mental health, etiquette, etc. He stressed that treating children as independent people treats children with equality and respect. On the issue of how to conduct family education in concrete terms, Locke proposed many practical methods, such as opposing the whip, advocating rational education, 
emphasizing the role of role models in children's education, and advocating that children should be properly rewarded and punished. Moral education. Rousseau, a famous French enlightenment thinker, published a monograph on family education titled "Emily Childhood Education" in the mid-18th century. In the book, Rousseau emphasized that education should adapt to nature, follow children's nature, and be consistent with children's age characteristics. Spencer, the British educator, pointed out in his book The Spencer's Happiness Education. Reduce Scolding and accusations will not bring good results. Therefore, Spencer believes that children's emotions should be adjusted to happiness, self-confidence, and concentration before learning.

Headings may be numbered or unnumbered ("1 Introduction" and "1.2 Numbered level 2 head"), with no ending punctuation. As demonstrated in this document, the initial paragraph after a heading is not indented.

\section{SIMILARITIES IN SINO-AMERICAN FAMILY EDUCATION}

Although China and the United States are two countries with great cultural differences, there are still many similarities in terms of family education. The following is mainly written about the similarities in nature and content.

\subsection{Life Meaning}

In the animal kingdom, families who live in the basic way of life do family education invariably. They exercise the survival ability of young children in various ways. Even after their growth, they will eventually achieve their ultimate independence by forced abandonment. They seem to know instinctively what kind of education is more beneficial to their children, and with the continued love of life, it is a wonderful and touching family education that seems to be merciless and effective. For all human beings, family education, in essence, has the meaning of life similar to the animal, which is guided by the love of the parents to realize the independent survival of the offspring.

\subsection{Cultural Implication}

China and the United States are two countries with great cultural differences. It can be said that they are the representatives of Eastern and Western cultures. However, there are still many similarities in family education, because the culture is in the end a kind of "group nature of people, group phenomenon. It is the nature and class phenomenon of class" (Li Shuyi , Li Xiaobing, 1987:7).

\subsection{Moral Education}

Moral value is the spiritual driving force of human behavior and it belongs to the human culture of the world. In fact, many moral views are consistent in all countries of the world, even if different cultures have different stories and traditions to teach them. In Chinese and American families, morality has always been the focus of family education. Sino-American morality arises from different cultural backgrounds and thus has different shades and different meanings. However, "love" and "goodness" have a common core, and they are also manifestations of human universal values. Starting from love, strive to be good. This is the common denominator of Sino-American morality.

\subsection{Intelligent Education}

Knowledge is the first productive force, which directly determines whether the country is prosperous and whether one can succeed. Therefore, China and the United States attach great importance to diligent reading in family education. China places reading in an important position. In ancient times, there were several purposes for reading, some for the official use of the imperial examinations, the establishment of fame and other secular utilitarian purposes, but also the idea of self-cultivation, for the country and the people. Of course, reading should be hard-working. From ancient times to the present, the maxims of diligent learning in the home training abound: "Live to old, learn to be old." There are also many hard-to-school allusions that are often used as a model for diligently learning children. For example, take children to libraries, bookstores, etc. They often encourage their children to ask more questions. They teach children how to solve problems through reading and thinking, inspire children's interest and desire for knowledge, and cultivate their innovative awareness and critical spirit.

\section{DIFFERENCE IN SINO-AMERICAN FAMILY EDUCATION}

China and the United States have great differences in terms of cultural traditions, thinking, lifestyle, and social customs, resulting in differences in educational methods, educational content, and educational purposes between China and the United States.

\subsection{Aims of Family Education}

Respecting the elders is a fine tradition of the Chinese nation. But for a long time, we have emphasized too much respect and obedience to the elders. Parents are accustomed to imposing their own thoughts and will on their children. This "patriarchal system" leads to children's dependence and loss of autonomy and initiative. In determining the goals of 
family education, parents also seldom consider the wishes of their children. Generally, parents make a final decision after comprehensively considering whether the child's progress in education, employment, and future achievements can be "brilliant". The ultimate goal of some Chinese family education is to hope that children will find a decent job and hope that their children will be able to benefit from their lives. The high expectations and strong utilitarian nature of Chinese family education have caused children's academic performance to receive great attention.

Parents in the United States believe that the purpose of home education is to prepare for survival. They emphasize self-cultivation and shaping, which has nothing to do with utilitarianism and career. Parents in the United States attach great importance to children's self-practice ability, such as labor and quality exercise. The most important thing for children is to learn how to overcome difficulties, increase courage, and find survival skills in complex environments. Parents respect and encourage children to "self-selection, selfresponsibility," and when setting goals for family education, parents will respect their children's wishes. The focus is on developing abilities to adapt to various environments. Parents pay more attention to children's overall development while paying attention to children's learning and intellectual development.

\subsection{Content of Family Education}

In general, China's family education follows the principle of "cultivating talents with all-round development of morality, intelligence, body, beauty, and labor". Affected by the current state of education in our country, when a child enters school, the intellectual education for bringing up children will rise to the top and there will be an imbalance. For parents to enter a prestigious university and find a good job, they would not hesitate to pay for the children's problems and report to the tutoring classes. However, this ability can only be tested and it has little to do with actual ability. In contrast, the content of family education in the United States is more plentiful and relaxed, and it can better reflect the spirit of "quality education." Parents aim to give children the ability to adapt to the society. From childhood to early childhood, they focus on strengthening their children's outdoor activities and physical activity, focusing on cultivating their interest in learning, inspiring their learning aspirations and expanding their cultural horizons.

The United States has very rich family education content. They focus on children's coordinated development in physical fitness, cognitive ability, sociality, and human emotion. Parents pay more attention to physical fitness and often organize outdoor activities and sports training. In raising children's cognitive abilities, parents attach importance to training children's different conscious organs, expand their cultural and artistic vision, and focus on stimulating children's interest in learning. In addition, parents encourage their children to participate in various group activities and allow them to learn to cooperate with others, share and help each other. In the cultivation of sentiments, parents often visit children's art museums and museums with their children to cultivate their artistic sentiments.

\subsection{Methods of Family Education}

The education method is the concrete measure and method that parents complete educational content. In American families, parents are very concerned about their free and equal interaction with their children. Parents respect children and they pay more attention to giving children more autonomy. This helps children to independently solve various problems in their daily life. At the same time, American parents often spend a lot of time with their children and communicate with their children on an equal basis. Therefore, American children can speak freely in front of their parents and freely express their opinions and real thoughts. American parents respect their children's different opinions and opinions and will not only deliberately suppress it, but also give more encouragement. In the eyes of some Chinese parents, children are always children and always want to do everything for their children.

In China, parents have absolute authority in the family. Parents play a leading role in the education of children and neglect the child's sense of independence. In the United States, the relationship between children and parents is relatively democratic. Parents' educational methods for children are mainly democratic and open. In the child's growth process, American parents encourage more children than protect them. They encourage children to bravely try and cultivate their self-confidence. Democracy and relaxed family education provide American children with the opportunity to express their ideas and decide things.

\section{CONCLUSION}

Family education is the foundation of all education. The family has made an initial and permanent foundation for one's life. Family education is irreplaceable. Since the generation and establishment of human family civilization, family education activities have been produced. For thousands of years, it has trained generations of children to stand on their own feet and to serve and benefit humanity. Family education has been inherited and enriched. The development of human culture has also maintained and promoted human social civilization. The child is an eternal topic and is also a chattering topic for parents today. According to the 
investigation of social hot issues in recent years, the issue of children's education has always been a hot spot of public concern.

In both Chinese and Western terms, there are many successful examples of both home-schooling concepts and their practices. It is not convincing to explain the right or wrong of their respective education concepts from individual examples. Therefore, we should promote the splendor of the splendid civilization of the Chinese nation for thousands of years, and at the same time we must adopt the democratic and open family education concept of the Western countries. In addition, parents should adjust their mentality, understand that not every child can become a learning point, each child has a different potential, as long as they pay hard, strong interest in learning, good habits, personality sound, mental health, is worth the father and mother's pride.

\section{REFERENCES}

[1] Collier, M. J, Thomas, M. Cultural Identity: An Interpretive Perspective [M]. Manchaester, UK: St. Jerome Publishing, 1988.

[2] Huabin Chen. Parents' Attitudes and Expectations Regarding Science Education [M]. Comparisons among American, Chinese-American, and Chinese Families, 2001.

[3] Lin C, Fu, VR. A Comparison of Child Rearing Practices among Chinese, Immigrant Chinese and Caucasian American Parents [M]. Child Development, 1990.
[4] Watson P J, Morris Ronald J. Individualist and Collectivist Values: Hypotheses Suggested by Alexis de Tocqueville [M]. The Journal of Psychology, 2002.

[5] Hofstede Geert. Cultural Constraints in Management Theories [M]. The Academy of Management Journal, 1993.

[6] Kim, Y. Y. Becoming Intercultural: An Integrative Theory of Communication and Cross Cultural Adaptation [M]. Manchester: St Jerome and American Bible Society, 2001.

[7] Lin C, Fu, VR. A comparison of child rearing practices among Chinese, immigrant Chinese and Caucasian American Parents [M]. Child Development, 1990.

[8] David Leiwei. Imagining the Nation: Asian American Literature and Cultural Consent [M]. Shanghai Foreign Language Education Press, 1998.

[9] Moon H. Jo, Daniel D. Changing images of Asian Americans [J]. International Journal of Politics, 1993. 2012, 33(01): 144-149.

[10] Michelle L. Kelley,Hui-Mei Tseng. Cultural Differences in Child Rearing: A Comparison of Immigrant Chinese and Caucasian American Mothers [M]. Journal of Cross Cultural Gerontology, 1992.

[11] Rutter, M.L. Child and adolescent psychiatry [M]. Heidelberg University, 1985. 